\title{
HOUSEHOLDS' WASTE MATERIAL MANAGEMENT AND RECYCLING: HOW MUCH CONCEIVABLE TO SUPPORT A ZERO-WASTE MANAGEMENT
}

\author{
Arif Ibne ASAD'; MD. Sohanur RAHMAN²; Samira AKTER ${ }^{2}$
}

${ }^{1} \mathrm{Ph} . \mathrm{D}$. candidate, Faculty of Management and Economics, Tomas Bata University Zlin, the Czech ${ }^{2}$ M.S.S, Department of Economics, Varendra University, Rajshahi, Bangladesh

\begin{abstract}
Purpose: The paper aims to understand household waste material management and recycling in Rajshahi City Corporation in Bangladesh and how much the city dwellers can support zero-waste management in the future. Design/methodology/approach: The investigation was based on a primary survey between 2019 and 2020. Researchers arbitrarily chose 120 family units; respondents were asked to answer a structural questionnaire on households' waste management (HWM), recycling and Perception to attain a zero-waste management goal. The analysis was done through descriptive statistics and logistic regression models. Findings: The respondents have a sound understanding of the health consequences of waste-related pollution. The logistic regression models demonstrated that education and awareness of households are positive and significantly related to recycling. Research limitations: Difficulties in looking at a randomly chosen holding number and the unwillingness of the household members to clarify their genuine pay level were the few troubles in the research. Practical implications: The study reveals that $88 \%$ of the respondents were known to HWM beforehand, and 54\% concurred to see a moderately vibe of local ambience compared to the past five years. Social implications: Our study would motivate to attain zero-waste management in the Rajshahi city in future as the households welcomed an approach of recycling, reducing or refusing to buy things with lots of packaging.
\end{abstract}

Keywords: Recycling, Household Waste Management, Logistic Regression Model, Rajshahi City Corporation.

\section{Introduction}

The importance of caring for the environment is becoming increasingly crucial in Bangladesh for a variety of reasons. On the one hand, as a developing nation, there is rapid industrialization and urbanization; on the other hand, balancing a population of 166.3 million with a fast growth rate is a challenge for the country. However, a high rate of environmental contamination has been noted, as well as a lack of success in environmental conservation efforts and every day, Bangladesh creates roughly 25000 tons of waste in its cities (UNDP, 2018). Even amid the darkness, however, there are some reasons to be optimistic; this is particularly true in Bangladesh. A Swedish International Development Cooperation and UNDP project launched in 2018 to southernmost point called "Teknaf "sub-district to support the solid waste management (SWM) and succeeded to attain a $10 \%$ recycling from the waste

https://doi.org/10.11118/978-80-7509-820-7-0091

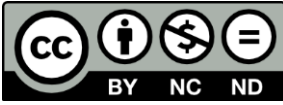


products of households and markets. Another encouraging news is that the northern divisional city, Rajshahi had the distinction of having the lowest drop of air pollution in the world in 2016 (Graham-Harrison, \& Doshi, 2016).

Importantly, it is better to start the zero-waste management program in urban homes with Rajshahi City Corporation since earlier achievements in environmental restoration and nurturing can be a big step forward for Bangladesh's zero-waste policy in the future. Furthermore, it is critical since developing countries lag behind industrialized economies in terms of recycling and domestic trash management. The developed world has a strong position in recycling, and people have a long history of doing so. Likewise, Germany, Austria, South Korea, Wales, and Switzerland are among the top five recycling countries in the world, with over $50 \%$ of municipal garbage recycled (Gray, 2017). In developing countries like Bangladesh, the rate is negligible, and there is little information available. There is huge study gap regarding the SWM and zero waste management system in the emerging third world counties, for-instance, in South Asia (Colona, Fawcettb 2006, p. 916) investigated in Indian megacities, and (Siddiqi et al. 2020, p.1) study in Karachi city Pakistan for metropolis waste material recycling.

The study's aim is to understand the household waste material management and recycling in Rajshahi City Corporation and how how much the city dwellers has the capability of supporting a zero waste management in future.

\section{Literature review / Research Background}

A timeline of the zero-waste movement has started earlier since 1970s while singleuse plastics became commonplace and using reused materials like aluminum have the potential to save energy and money. Bea Johnson, a French American residing in California, is widely recognized with founding the zero-waste lifestyle movement by starting the practice to her small family with four members and documenting her journey on her blog Zero Waste Home (Zerowaste Blog, 2020). The concept of zero waste management is currently gaining momentum in business and circular economic aspects, such as eeconomic cost, economic benefits, and incentives are three fundamental economic sectors of the zero- waste management concept, Zaman (2014). In addition, it has anticipated benefit by creating a circular economy that has a lower environmental impact and emits less $\mathrm{CO} 2$, less demand for costly, scarce resources and new employment sector in waste management, recovery, and reuse (European Commission Environment, Consumers \& Health, 2021).

The goal of our literature analysis is to look at household waste management around the world to see what opportunities there are for further research in developing countries. (Abdullah, Salleh, Ismail 2017, p. 38) study focused on how households are well-informed about home solid waste management and how they feel about the services offered by a solid waste management concessionaire in one of Malaysia's areas, (Ayçin, Kaya 2021, p.1) intends to uncover potential impediments that have a significant influence in Turkey's zero waste management practices. There are studies on post consumption waste, and resource depletion, such as (Matete ,Trois 2008, p. 1480) tried to integrate a Zero Garbage techniques into an existing integrated 
waste management system and to offer a Zero Waste model for post-consumer waste in South African metropolitan neighbourhoods. ( Zaman, Lehmann 2011b, p. 73) paper has the goal is to better understand the fundamental elements that influence waste management systems in cities, such as consumption, resource depletion, and the possibility of decoupling through the implementation of the "zero waste city" idea. (Babaei et al. 2015, p. 94; Chikowore 2021, p, 386; Xu et al. 2016, p. 377) examined the relationship between socio-demographic characteristics (age, education, gender) and solid waste management knowledge, attitude, and practice.

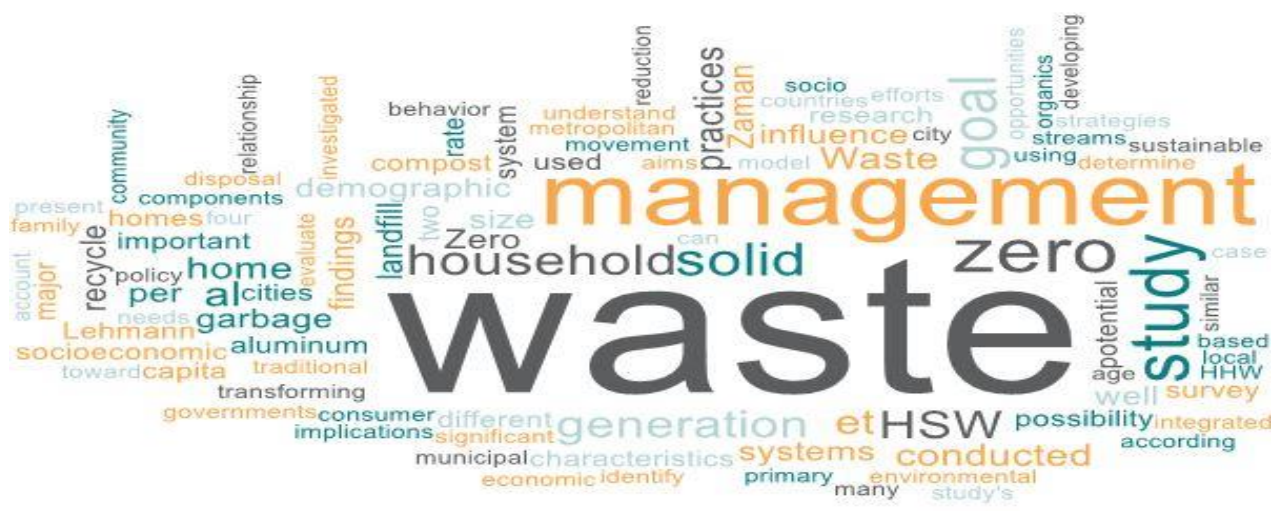

Figure 1: Word Cloud from Literature Review, source: Authors (2021).

The present study aims to discuss the scenario of households' waste material management and recycling of Rajshahi City Corporation in Bangladesh how much it is conceivable to back a zero-waste administration framework in the future. Furthermore, the study aims to determine the effects of Bangladesh education on people's perceptions of recycling as well as environmental consciousness how substantially impacts on it. Accordingly, we derive the following hypothesis:

Hypothesis 1: Households perception of recycling is poitively influenced by their belief that education increases the motivation of recycling.

Hypothesis 2: The previous awareness households for environment motivates to believe that the higher the prior consciousness, the higher will be motivations to accept recycling in their daily chorses.

\section{Methodology}

The study was based on field survey in Rajshahi City Corporation with having two stage random sampling method. while researchers collected the data in 2019 from twelve randomly chosen city wards out of 30 Wards, such as ward number: 3,4, $11,13,19,21,23,24,25,27,28$, and 29. After selecting those Rajshahi city wards, the researchers randomly chose 10 households from all the wards for interview and at the end we collected total 120 samples for our study. The respondents were asked 
to answer a structural questionnaire regarding their households' waste material management. The questionnaire was prepared from prior literature review of high rank journals from Web of Science, Scopus, the Chartered Association of Business Schools (CABS) Journals and high-cited papers from Google Scholar.

In the random sampling process, researchers conducted the respective city wards councilor office and collected the holding numbers of households as a population list, chose ten sample from these list while research randomizer online application was used. The surveyed data set was coded in excel spreadsheet and analysed by descriptive statistics and logistic regression model typically for hypothesis testing. The core variables in the research concerned on socio-demographic features of households, economic conditions, environmental awareness, Perception of recycling and environmental sustaibilty. There has been used logistic regression model to understand the relationships between dependent and independent variables, while Perception of recycling is regressed educational factors and environmental initiatives.

\section{Table 1: Logistic Regression models}

\begin{tabular}{|c|c|}
\hline $\begin{array}{l}\text { Model 1: } \\
\qquad \begin{aligned} \text { Per_recycly }= & \alpha_{1}+\alpha_{2} \text { edu } \\
& +\alpha_{3} \text { prev_edu } \\
& +\alpha_{4} \text { pres_edu }+u t\end{aligned}\end{array}$ & $\begin{array}{l}\text { Model 2: } \\
\begin{aligned} \text { Per_recycle }= & \beta_{1}+\beta_{2} \text { ask_separion } \\
& +\beta_{3} \text { collection_problem } \\
& +\beta_{4} \text { incentive }+v t\end{aligned}\end{array}$ \\
\hline $\begin{array}{l}\text { Per_recycly = Perception of recycling } \\
\boldsymbol{\alpha}_{\mathbf{1}}=\text { intercept } \\
\text { edu =education attainment } \\
\text { prev_edu= previous education } \\
\text { concerning environment } \\
\text { pres_edu= present education } \\
\text { concerning environment } \\
\text { ut= error term }\end{array}$ & $\begin{array}{l}\text { Per_recycly = Perception of recycling } \\
\boldsymbol{\beta}_{\mathbf{1}}=\text { intercept } \\
\text { ask_separion= ask for separating } \\
\text { household waste materials } \\
\text { collection_problem = city corporation } \\
\text { collection major problem for recycling } \\
\text { incentive= incentives for recycling } \\
\mathbf{v t}=\text { error term }\end{array}$ \\
\hline
\end{tabular}

Source: Authors (2021)

\section{Results}

Descriptive Statistics on Socio-demographic features: The key findings demonstrated that around $70 \%$ of the respondents are female as female members in a family more connected with the environmental issues as well as household chores and waste management of the household. 


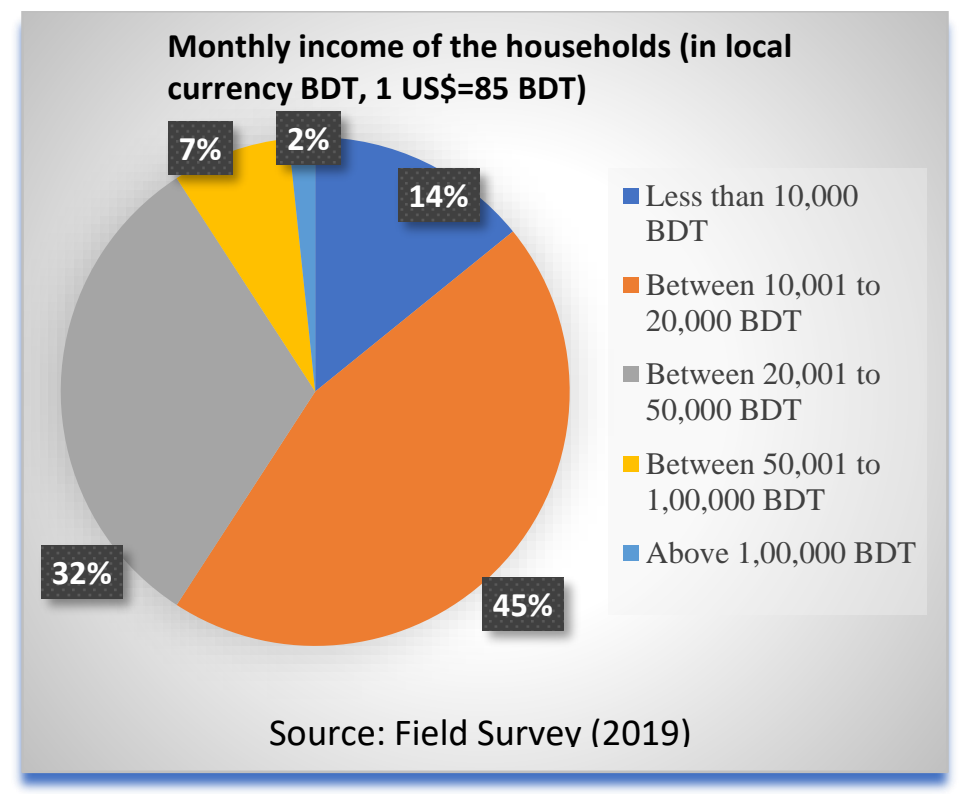

Figure 2: In the sample area, the average household income is between BDT 10,001 to 20,000.

While the currency rate was in 06.06.2021, 1 US\$=85BDT.

Figure 3 illustrates that around $33 \%$ respondents have secondary level education and $27 \%$ approximately have minimum bachelor degrees. Therefore, the education level is quite satisfactory in the study area. Figure 4 shows that majority of the people are either doing business or service holders under public or private sectors.

\section{Figure 2: The monthly income of households in local currency BDT.}

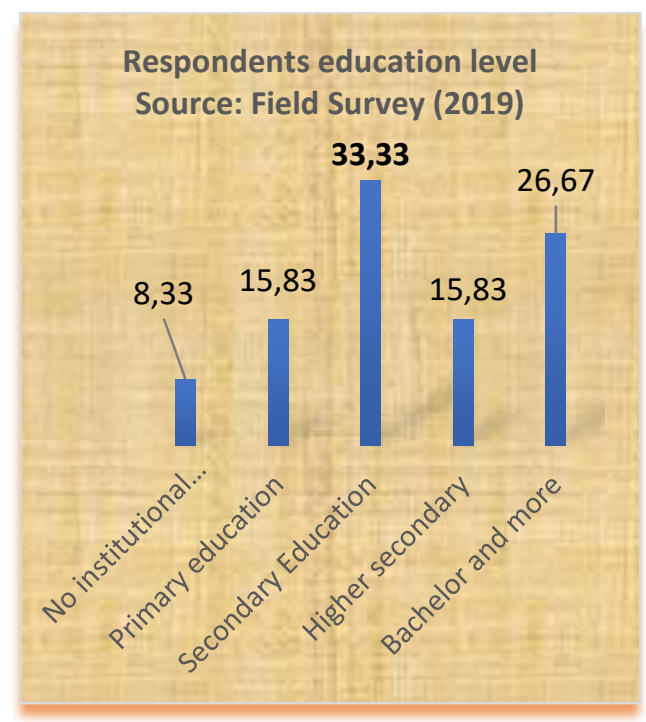

Figure 3: Respondent education level

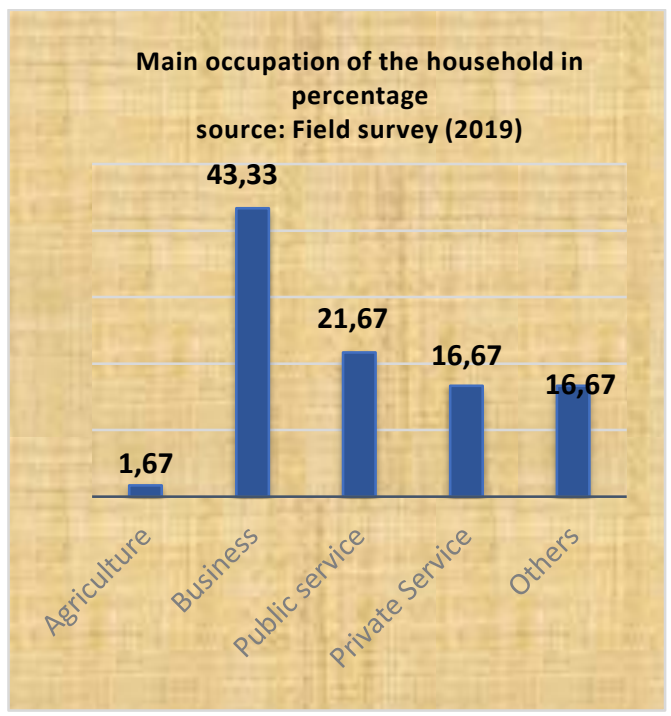

Figure 4: Main occupation of the households

The data set also implies that the average household members are around five and approximately $61 \%$ members are between the age group (30-49 years). Therefore, it is the strength for our study to motivate the adult because they have better 
experiences about environment and the practicalities. Another interesting result is that the average life span on living Rajshahi city is more than 20 years and that means households are living for a long time and have been adapted themselves with the environmental conditions of the Rajshahi Metropolitan Area.

Household Waste Management Awareness: 88\% respondents had the HWM idea beforehand, and the major sources for receiving environmental related information is Television, friends and relatives, newspapers while internet sources have a little impact on it. Around $81 \%$ people received the idea from their previous level schooling (primary and high schools). The researchers asked why it is prominent to take care of the household garbage, they could only choose among the options, such as hazardous impact on human health $(41.64 \%)$, detrimental effect on environment (34.17\%), the wastes look ugly and smells irritating (22.5\%), and others (1.67\%). As majority of the household responded that environmental preservetation is crucial for health purpose, the resercher asked the health condition by emphasizing on suuffering any diseases of a family mebers during the last six weeks, the result shows that 59\% households did not suffer by any of the diseases while others either have one or two of the following health issues, such as $18 \%$ have cough and breathing problems, $10 \%$, fever, $10 \%$ diarrhea as well,4\% skin problem. All these diseases any how related to the environment of the households, therefore, they were conserened about the health issues more than other options.

Waste Management by Rajshahi City Corporation and Households: Most of the families $98 \%$ put the waste materials in a bucket and $2 \%$ keep public bin or plastic bags. $96 \%$ household empty the bucket once in a day and other $4 \%$ empty the garbage once in two days. Out of 120 respondents, 118 replied a positive feedback of city corporation household waste collection system and they put the waste to the city corporation waste collection vehicle, which is collected once in a day. Around $84 \%$ households have come to know about the recycling process beforehand. And $88 \%$ agreed to separate their daily household products for recycling. Only $3 \%$ households expect incentives to start recycling work and 54\% concurred to see a moderately vibe of local ambience compared to the past five years

Table 2. Households' initiatives for HWM and environmental success.

\begin{tabular}{|c|c|c|c|c|}
\hline \multicolumn{5}{|c|}{ The initiatives undertaken by households } \\
\hline $\begin{array}{l}\text { Level of } \\
\text { cooperation }\end{array}$ & $\begin{array}{l}\text { Agreed and asked } \\
\text { local government } \\
\text { to take initiatives } \\
\text { on it. }\end{array}$ & $\begin{array}{l}\text { Agreed } \\
\text { but yet } \\
\text { not asked. }\end{array}$ & $\begin{array}{l}\text { Agreed but not } \\
\text { do any } \\
\text { cooperation. }\end{array}$ & $\begin{array}{l}\text { Think it is } \\
\text { impossible to } \\
\text { have } \\
\text { recycling }\end{array}$ \\
\hline Percentage & $14 \%$ & $60 \%$ & $22 \%$ & $4 \%$ \\
\hline \multicolumn{5}{|c|}{ How much households gained environmentally in last five years? } \\
\hline $\begin{array}{c}\text { Too much } \\
\text { improvement }\end{array}$ & $\begin{array}{c}\text { Moderate } \\
\text { improvement }\end{array}$ & $\begin{array}{c}\text { As } \\
\text { identical }\end{array}$ & $\begin{array}{c}\text { Little } \\
\text { unfavorable }\end{array}$ & $\begin{array}{l}\text { Extremely } \\
\text { bad }\end{array}$ \\
\hline $34 \%$ & $54 \%$ & $9 \%$ & $3 \%$ & $0 \%$ \\
\hline
\end{tabular}

Source: Authors (2021) 
Empirical Findings: The logistic regression is classified in two models, the first model while Perception of recycling is regressed by educational factors, such as present educational status of the respondent, previous education concerning environment and present education concerning environment. Overall, education has a positive impact on the Perception of recycling. While the education is significant at $5 \%$ with a stronger coefficient. On the other hand, the second model has been regressed with having identical dependent variable but environmental initiatives are regressors. The household is expected to acept the sorting of household waste materals for the purpose of recycling. The coefficient is 2.237170 and significant at $1 \%$ level. There is a great chance that the recycling project will be effective among the households if the initiatives are taken through proper channel. As the households believe the collection of sorted matewrals by the Rajshahi City Corporation is not a problem, so that whether collection is a problem, is negatively related to the Perception of recycling but statistically insignificant.

\section{Table 3: Logistic Regression models}

\begin{tabular}{|c|c|c|c|}
\hline \multicolumn{4}{|c|}{ Estimation results of regressed variable Perception of recycling } \\
\hline Variables & Model 1 & Variables & Model 2 \\
\hline Intercept $\left(\alpha_{1}\right)$ & $\begin{array}{c}-0.506023 \\
{[-0.46]}\end{array}$ & Intercept $\left(\beta_{1}\right)$ & $\begin{array}{l}-0.687053 \\
{[-0.29]}\end{array}$ \\
\hline edu $\left(\alpha_{2}\right)$ & $\begin{array}{l}0.433841^{*} \\
{[1.78]}\end{array}$ & ask_separion $\left(\beta_{2}\right)$ & $\begin{array}{l}2.237107^{* * *} \\
{[3.57]}\end{array}$ \\
\hline prev_edu $\left(\alpha_{3}\right)$ & $\begin{array}{l}1.552732^{* *} \\
{[2.37]}\end{array}$ & collection_problem $\left(\beta_{3}\right)$ & $\begin{array}{l}-0.219831 \\
{[-0.43]}\end{array}$ \\
\hline pres_edu $\left(\alpha_{4}\right)$ & $\begin{array}{l}0.074338 \\
{[0.17]}\end{array}$ & incentive $\left(\beta_{4}\right)$ & $\begin{array}{l}0.300236 \\
{[0.27]}\end{array}$ \\
\hline $\mathrm{R}$-square & 0.1712 & R-square & 0.1236 \\
\hline Obs & 120 & Obs & 120 \\
\hline
\end{tabular}

\section{Discussion}

Education and prior knowledge are effective factors in the research, Cole et al. (2014), it is urgent to switch the focus from recycling to reuse, and the priority of increasing educational activities will tend to change household behaviours on environmental preservation. The respondents from Rajshahi city corporation have well understanding on health consequences of waste related pollution. The respondents were asked with an open-ended question on the main reason for protecting the metropolitan's environment, the answer was very straightforward with majority comments on having a healthy environment to keep sound health which is crucial for the future betterment. Abdullah et al. (2017), has identical finding on the health consequence of waste management. The second core issue of our research was based on the initiatives undertaken by households reflecting the awareness. For instance, 56\% households receive the available information and particularly $46 \%$ 
have prior idea on sustainable development in the study. Babaei et al. (2015) and Abdullah et al. (2017) found improvement in citizens awareness to promote sustainable waste recycling program. It requires to develop effective public campaigns, affordable and practicable plans relevant to local administrative framework (Zaman \& Lehman, 2011a; Zorrpas et al. 2015) and try to develop an interior behavioural culture in SWM and reach the zero waste in future (Zaman \& Lehman, 2011b; 2015; Babaei et al. 2015). Sustainable waste management practices yet have to meet a critical mass of success, Zotos et al. (2009), lack of financial aid is a key barrier of SWM (Aycin\& Kaya, 2021), particularly the proposition of zero waste management is not a well-suited issue in developing countries, like Bangladesh, India and Pakistan where recycling has yet not started with a mass success. Motivation as well as promises can play vital role there, (Colon \& Fawcett, 2006; Babaei, et al. 2015).

\section{Conclusion}

The responsible behaviour by the households raises potential scope of recycling and zero waste management in Bangladesh. A push environmental development strategy by legal authority can be expected to reach the goals of sustainable environment. Importantly, education plays a crucial role in acquiring the basics of recycling and households waste management. The Rajshahi city corporation has a few successes in environmental conservation, but the government and local NGOs must fight for the formation of a household culture of minimal waste pollution and expected to turn into a zero-waste management system.

\section{Acknowledgements}

The research was supported by a grant from the Center for Interdisciplinary Research (CIR), Varendra University, Rajshahi, Bangladesh. The authors thank Professor Rashidul Haque, Honorable Pro-Vice Chancellor, VU, for his constant encouragement and support in this research. The authors declare no conflict of interest with respect to the research reported herein. The authors would like to express their gratitude to the Internal Grant Agency (IGA), Faculty of Management and Economics (FAME), 2020 (006), Tomas Bata University Zlin, for their assistance in completing the full paper proceedings at ICOM 2021.

\section{References}

1. Abdullah, Z. ,Salleh, S. M., \& Ismail, K. N.I.K. (2017). Survey of Household Solid Waste Management and Waste Minimization in Malaysia: Awareness, Issues and Practices, "International Journal of Environmental \& Agriculture Research (IJOEAR)", 12, 3, pp. 38 48.

2. Ayçin, E.\& Kaya, S. K. (2021). Towards the circular economy: Analysis of barriers to implementation of Turkey's zero waste management using the fuzzy DEMATEL method, "Waste Management and Research", pp. 1-12. doi: 10.1177/0734242X20988781 
3. Babaei, A.A. et al. (2015). Household recycling knowledge, attitudes and practices towards solid waste management, "Resources, Conservation and Recycling" , 102, pp.94-100. https://doi.org/10.1016/j.resconrec.2015.06.014

4. Chikowore, N. (2021). Factors infuencing household waste management practices in Zimbabwe, Journal of Material Cycles and Waste Management 23, pp.386-393. https://doi.org/10.1007/s10163-020-01129-9

5. Cole, C. et al. (2014). Towards a Zero Waste Strategy for an English Local Authority, “ Resources, Conservation and Recycling” , 89, pp.64-75. http://dx.doi.org/10.1016/j.resconrec.2014.05.005

6. Colona, M. \& Fawcett, B. (2006). Community-based household waste management: Lessons learnt from EXNORA's 'zero waste management' scheme in two South Indian cities,'Habitat International”, 30, pp. 916-931. doi:10.1016/j.habitatint.2005.04.006

7. European Commission Environment, Consumers \& Health, (2021). Benefits of a Zero Waste Economy (Circular Economy). https://www.ecos.ie/benefits-zero-circular-economy/ (access date: 19.05.2021).

8. Graham-Harrison, E. \& Doshi, V. (2016). Rajshahi: the city that took on air pollution - and won. The Guardian Retrieved from: https://www.theguardian.com/world/2016/jun/17/rajshahibangladesh-city-air-pollution-won/ (access date: 19.05.2021).

9. Gray, A. (2017). Germany Recycles More than any Other Country. World Economic Forum. https://www.weforum.org/agenda/2017/12/germany-recycles-more-than-any-other-country/ (access date: 19.05.2021).

10. Matete ,N. \& Trois, C.(2008). Towards Zero Waste in emerging countries - A South African experience, "Waste Management", 28, pp.1480-14. https://doi.org/10.1016/j.wasman.2007.06.006

11. Siddiqi, M. M. et al. (2020). Exploring E-Waste Resources Recovery in Household Solid Waste Recycling, "Processes", 8(9), 1-13. https://doi.org/10.3390/pr8091047

12. UNDP (2018). Sustainable Solutions to Solid Waste Project. https://www.linkedin.com/posts/undpbangladesh sustainable-solutions-to-solid-waste-in-coxsactivity-6801934103353663488-MwtA (access date: 29.06.2021).

13. $\mathrm{Xu}, \mathrm{L}$. et al. (2016). Path analysis of factors influencing household solid waste generation: a case study of Xiamen Island, China, "Journal of Material Cycles and Waste Management", 18, pp.:377-384.

14. Zaman, A. U. \& Lehmann, S. (2011a). Urban growth and waste management optimization towards 'zero waste city', 'City, Culture and Society", 2, pp. 177-187. http://dx.doi.org/10.1016/j.ccs.2011.11.007

15. Zaman, A. U. \& Lehmann, S. (2011b). Challenges and Opportunities in Transforming a City into a "Zero Waste City", "Challenges", 2, pp. 73-93; doi:10.3390/challe2040073

16. Zaman, A. U. (2014). Identification of key assessment indicators of the zero waste management systems, "Ecological Indicators",36, 682-693. doi:10.1016/j.ecolind.2013.09.024

17. Zero waste Blog (2020). Who started the zero-waste movement? https://www.zerowaste.com/blog/what-is-it-who-started-the-zero-waste-movement/(access date: 19.05.2021)

18. Zorpas, A.A. et al. (2015). Household waste compositional analysis variation from insular communities in the framework of waste prevention strategy plans, "Waste Management", 38, pp.3-11. http://dx.doi.org/10.1016/j.wasman.2015.01.030 